\title{
Assessment of quality of life and associated factors among people with epilepsy attending at Amanuel Mental Specialized Hospital, Addis Ababa, Ethiopia
}

\author{
Minale Tareke Tegegne ${ }^{1}$, Niguse Yigzaw Muluneh ${ }^{2}$, Teketel Tegegne Wochamo ${ }^{3}$, \\ Andargie Abate Awoke ${ }^{4}$, Tilahun Belete Mossie ${ }^{5}$, Molla Ayele Yesigat ${ }^{6}$ \\ ${ }^{1}$ Department of Psychiatry, Dessie Referral Hospital, Dessie, Ethiopia \\ ${ }^{2}$ Department of Psychiatry, College of Medicine and Health science, University of Gondar, Gondar, Ethiopia \\ ${ }^{3}$ Department of Psychiatry, Faculty of Medicine, Addis Ababa University, Addis Ababa, Ethiopia \\ ${ }^{4}$ College of Medicine and Health science, Bahir Dar University, Bahir Dar, Ethiopia \\ ${ }^{5}$ Department of Psychiatry, Felege Hiwot Referral Hospital, Bahir Dar, Ethiopia \\ ${ }^{6}$ Department of Psychiatry, Federal Ministry Health, Addis Ababa, Ethiopia
}

\section{Email address:}

minale23@gmail.com (M. T. Tegegne),neglideta@yahoo.com (N. Y. Muluneh), abeltek2006@yahoo.com (T. T. Wochamo), andargie_abate@yahoo.com (A. A. Awoke), tilahun100@gmail.com (T. B. Mossie), mollaayele@gmail.com (M. A. Yesigat)

\section{To cite this article:}

Minale Tareke Tegegne, Niguse Yigzaw Muluneh, Teketel Tegegne Wochamo, Andargie Abate Awoke, Tilahun Belete Mossie, Molla Ayele Yesigat. Assessment of Quality of Life and Associated Factors among People with Epilepsy Attending at Amanuel Mental Specialized Hospital, Addis Ababa, Ethiopia. Science Journal of Public Health. Vol. 2, No. 5, 2014, pp. 378-383.

doi: $10.11648 /$ j.sjph.20140205.12

\begin{abstract}
Background: There is shortage of literature on the impact of epilepsy on quality of life (QoL). We conducted a study to assess the quality of life and associated factors among epileptic patients in Ethiopia. Method: An institution based cross -sectional study was conducted From April to May, 2013, among 423 samples of epileptic patients from outpatient department of Amanuel Mental Specialized Hospital. Quality of life was assessed using world Health Organization Quality of Life questionnaire (WHO QOL BREF) scale; in addition, perceived stigma scale and Hospital Anxiety and Depression scale were used for interviewing the study participants. Logistic regression analysis was done to identify factors associated with quality of life. Result: A total of 415 epileptic patients were included in this cross-sectional study. Out of which, $45.8 \%$ of the study participants had poor quality of life. Respondents who are unable to read and write, primary school, those who had frequent seizures, taking more than one type of antiepileptic drugs, anxiety, depression and perceived stigma, were found to be significantly associated with poor quality of life. Conclusion: Poor quality of life was found to be high among epilepsy patients. Managing patients with epilepsy to become seizure free, educating people regarding epilepsy and treatment of co-morbid disorders will help to improve quality of life in patients with epilepsy.
\end{abstract}

Keywords: Epilepsy, Quality of Life, Depression, Anxiety

\section{Background}

Epilepsy is one of the most common and serious brain disorders in the world that affects at least 50 million people worldwide .This could be underestimated, as partial seizures are often not recognized as such in the developing world [1].

Epilepsy can be associated with profound physical, psychological and social consequences and its impact on a person's quality of life can be greater than that of many other chronic diseases because of different factors [2].

Many people in Africa also believe that epilepsy is contagious and that can be spread by urine, saliva, flatus, or feces excreted at all times or during a convulsion because of these unwilling to help or to touch the person who has fallen during a seizure [1, 3].These enormous social stigmas lead epileptic patients to have lower quality of life (QOL) [4].

WHO defined quality of life as individuals" perceptions of their position in life in the context of the culture and 
value systems in which they live and in relation to their goals, expectations, standards and concerns". It is a broad concept consists of the subjective assessment of his or her physical health, psychological state, and level of independence, social relationships, and their relationships to the environment[5].

People living with epilepsy (PLWE) in developed world have significant impairment in their health related quality of life (HRQOL) [6]. However, in Africa where the world highest prevalence data regarding PLWE present, few studies concerning HRQOL have been published [7].

\section{Methods}

\subsection{Study Settings and Population}

From April to May, 2013, we conducted a cross sectional study at Amanuel Mental Specialized Hospital (AMSH) in Addis Ababa. The Study Population was epileptic patients who had treatment follow up during study period. Sample size was determined using a single population proportion formula. Due to absence of data in the country; proportion of population living with epilepsy and who had poor QOL was assumed $50 \%$, and by adding $10 \%$ contingency for non response rate, a total of 423 study populations were involved. Patient whose ages were 18 years and above, with diagnosis of epilepsy and under treatment with one or more antiepileptic drugs from the outpatient units for at least 6 months were included in the study. Systematic random sampling method was used to select study population coming to AMSH during the study period. Patients with serious general medical condition and unable to communicate were excluded.

\subsection{Data Collection and Tools}

Data was collected by using a structured questionnaire regarding socio-demographic characteristics and clinical factors of epilepsy. Concerning quality of life, co-morbid anxiety, depression and stigma, World Health Organization Quality of Life questionnaire (WHO QOL BREF) scale, Hospital Anxiety and Depression scale (HADS) and stigma scale were used respectively and face to face interview was employed to obtain the data.

WHOQOL-BREF contains 26 items and a sound, crossculturally valid assessment of QOL, consisting of four domains: physical health (7 items), psychological health (6 items), social relationships (3 items), and environmental health (8 items); it also contains the first two questions on general perception of life and health[8]. This WHOQOL is probably the most widely used health-related quality of life measure in the world with about 58 national versions[9].Each individual item of the WHOQOL-BREF is scored from 1 (very dissatisfied/very poor) to 5 (very satisfied/very good). According to instruction manual, raw scores for the domains of WHOQOL-BREF were calculated and were transformed on the scale ranging from 0 to 100 , where 100 the highest and 0 the lowest QOL[5]. The mean score of each domain and the total score were also calculated since quality of life measures in studies are often presented as means[10].

Therefore, categorization was done using the mean scores of WHOQOL-BREF. Subjects were categorized as having GOOD QOL in WHOQOL-BREF, those scores greater than or equal to mean (M). While subjects with values less than the mean $(\mathrm{M})$, were categorized as having POOR QOL [11].

HADS is a 14-item questionnaire, commonly used to screen for symptoms of anxiety and depression. The 14items can be separated into two 7-item sub-scales for anxiety and depression. HADS scale was validated in Ethiopia. The scales use a cut -off score for anxiety and depression of greater than or equal to 8 [12]. Data was collected by three trained diploma psychiatry nurses and one supervisor (BSc nurse) for a period of approximately one month.

\subsection{Data Quality Assurance}

All questionnaire were translated into the local language Amharic and then translated back into English by expertise and senior psychiatrist and $5 \%$ of the questionnaire were pre-tested on epileptic patients at AMSH before two days prior to data collection. Two day training was given to orient data collectors and supervisor on the questionnaire.

\subsection{Data Processing and Analysis}

The coded Data was checked, cleaned and entered into Epi Info version 3.5.4 and then exported into SPSS window version 20.0 for analysis.

Logistic regression was performed to assess the association between binary outcomes and different explanatory variables. Bivariate analysis was first conducted for each potentially explanatory risk factor. The strength of association was interpreted using odds ratio and confidence interval. P-value $<0.05$ was considered statistically significant in this study.

\subsection{Ethical Consideration}

Ethical clearance was obtained from University of Gondar and AMSH. Written informed consent was obtained from the study participants. To ensure confidentiality, names or identifying information were not indicated on the questionnaires

\section{Result}

\subsection{Socio-Demographic Characteristics of the Respondents}

Of the total 423 study participants enrolled, 415 were interviewed; with response rate $98 \%$, of which $229(55.2 \%$ ) males were participated in the study. One hundred seventy seven $(42.7 \%)$ of the respondents lie in the age group between 25-34 years whereas the median age were 28 years ranging from $18-72$ years. 
Table 1. Distribution of participants by socio-demographic Characteristics at Amanuel mental specialized Hospital, Addis Ababa, $2013(n=415)$

\begin{tabular}{|c|c|c|c|}
\hline Variable & & Number & Percentage (\%) \\
\hline \multirow{2}{*}{ Sex } & Male & 229 & 55.2 \\
\hline & Female & 186 & 44.8 \\
\hline \multirow{4}{*}{ Age } & $18-24$ & 130 & 31.3 \\
\hline & $25-34$ & 177 & 42.7 \\
\hline & $35-44$ & 68 & 16.4 \\
\hline & $45+$ & 40 & 9.6 \\
\hline \multirow{3}{*}{$\begin{array}{l}\text { Marital } \\
\text { status }\end{array}$} & Single & 255 & 61.4 \\
\hline & Married & 146 & 35.2 \\
\hline & Divorced/Widowed & 14 & 3.4 \\
\hline \multirow{3}{*}{ Residence } & Urban & 351 & 84.6 \\
\hline & Rural & 64 & 15.4 \\
\hline & Orthodox & 278 & 67.0 \\
\hline \multirow{3}{*}{ Religion } & Muslim & 84 & 20.2 \\
\hline & Protestant & 47 & 11.3 \\
\hline & All others & 6 & 1.4 \\
\hline \multirow{5}{*}{ Ethnicity } & Amhara & 158 & 38.1 \\
\hline & Oromo & 121 & 29.2 \\
\hline & Gurage & 93 & 22.4 \\
\hline & Tigre & 26 & 6.3 \\
\hline & Others & 17 & 4.1 \\
\hline \multirow{4}{*}{$\begin{array}{l}\text { Educational } \\
\text { status }\end{array}$} & $\begin{array}{l}\text { Unable to write and } \\
\text { read }\end{array}$ & 35 & 8.4 \\
\hline & Primary school & 151 & 36.4 \\
\hline & Secondary school & 156 & 37.6 \\
\hline & Diploma and above & 73 & 17.6 \\
\hline \multirow{3}{*}{ Occupation } & With Job & 324 & 78.1 \\
\hline & Without Job & 91 & 21.9 \\
\hline & $<200$ & 117 & 28.2 \\
\hline \multirow{3}{*}{$\begin{array}{l}\text { Monthly } \\
\text { income }\end{array}$} & $200-500$ & 110 & 26.5 \\
\hline & $501-1000$ & 103 & 24.8 \\
\hline & $>1000$ & 85 & 20.5 \\
\hline
\end{tabular}

Table 2. Distribution of participants by clinical factors at AMSH, Addis Ababa, 2013(n=415)

\begin{tabular}{llll}
\hline Variable Name & & Frequency & Percent \\
\hline \multirow{2}{*}{ Duration of } & $\leq 5$ years & 146 & 35.2 \\
illness & 6-10years & 127 & 30.6 \\
& $\geq 11$ years & 142 & 34.2 \\
Age at onset of & <10 years & 53 & 12.8 \\
illness & 20-19 years & 161 & 38.8 \\
& $\geq 30$ years & 147 & 35.4 \\
Frequency of & $\geq 1 /$ month & 54 & 13.0 \\
seizure & 1-3/year & 229 & 54.9 \\
& Seizure free for 1year & 58 & 129 \\
Type of drugs & One & 257 & 31.1 \\
Side effects of & >two & 158 & 61.9 \\
AED & Yes & 197 & 38.1 \\
Medication & No & 218 & 47.5 \\
duration & 65years & 232 & 52.5 \\
& $\geq 10$ years & 79 & 55.9 \\
Perceived stigma & Yes & 104 & 25.0 \\
Ever use & No & 169 & 40.7 \\
substance & Yes & 246 & 59.3 \\
current use & No & 53 & 12.8 \\
substance & Yes & 362 & 87.2 \\
\hline & No & 29 & 7.0 \\
& & 386 & 93.0 \\
\hline
\end{tabular}

Majority of the study participants were single $(61.4 \%)$, urban dwellers (84.6\%), and orthodox followers (67.0\%).Amhara (38.1\%)followed by Oromo (29.1\%) by ethnicity and regarding educational status $37.3 \%$ attended secondary school followed by primary school $35.7 \%$ (Table 1 ).

\subsection{Clinical Characteristics of the Respondents}

Regarding duration of the illness among study subjects $35.2 \%$ had duration up to five years, followed by $34.2 \%$ eleven years and above. Concerning age at onset of illness $38.8 \%$ found between 10-19 years and 35.4\% found between 20-29 years. Most of the respondents (54.9\%) had one or more seizure attacks per month, $61.9 \%$ were under monotherapy (using single antiepileptic drugs) and 38.1\% were using two or more antiepileptic drugs. One hundred sixty nine $(40.7 \%)$ report perceived stigmatized by other people because of their illness (Table2).

Regarding co-morbidity, out of the total respondents $33.5 \%, 32.8 \%$ had anxiety and depression symptoms, respectively (figure 1).

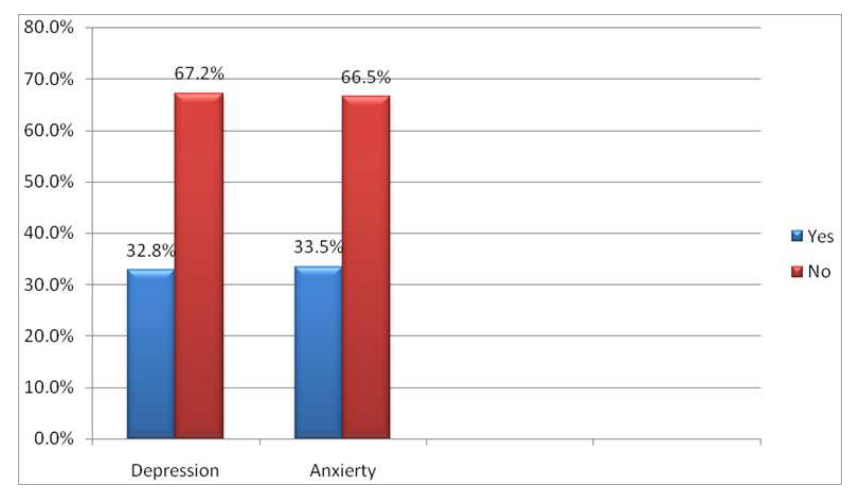

Figure 1. Frequency of depression and anxiety symptoms among epileptic patients attending at AMSH, 2013

\subsection{WHOQOL-BREF (0-100) Characteristics of Respondents}

The mean (SD) total score on the WHOQOL-BREF scale in this study was $56.36 \pm 13.37$. Out of the total 415 study participants, $45.8 \%$ had poor quality of life.

The WHOQOL BREF covers four different domains of quality of life, physical, psychological, social and environmental (Table3).

Table 3. Distribution of four domains of WHO QOL- BREF among epileptic patients at AMSH, Addis Ababa Ethiopia, $2013(n=415)$

\begin{tabular}{llll}
\hline Variables & Mean \pm SD & $\begin{array}{l}\text { Poor QOL } \\
\text { Frequency } \\
(\%)\end{array}$ & $\begin{array}{l}\text { Good QOL } \\
\text { Frequency } \\
(\%)\end{array}$ \\
\hline $\begin{array}{l}\text { Physical domain } \\
\text { Psychological } \\
\text { domain }\end{array}$ & $(56.02 \pm 14.62)$ & $183(44.1)$ & $232(55.9)$ \\
$\begin{array}{l}\text { Social domain } \\
\text { Environmental } \\
\text { domain }\end{array}$ & $(55.41 \pm 14.58)$ & $198(47.7)$ & $217(52.3)$ \\
\hline
\end{tabular}

\subsection{Association of Demographic and Clinical Variables with Quality of Life}

On bivariate analysis the factors found to fulfill the minimum requirement ( $\mathrm{p}$-value $<0.2$ in this study) were 
entered in to multivariate logistic regression for further analysis in order to control confounding effects.

The results of multivariate analysis showed that quality of life was significantly associated with educational level, frequency of seizure, types of drugs, co-morbid depression, anxiety and perceived stigma.

It was found that lower educational level was significantly associated with poor quality of life. Being unable to read and write was 4.6 times $(\mathrm{AOR}=4.69,95 \% \mathrm{CI}$ : $1.38,15.87)$ and respondents of primary school were 3.5 times $(\mathrm{AOR}=3.51,95 \% \mathrm{CI}: 1.57,7.82)$ more likely to have poor quality of life as compared to respondents with education level of diploma and above.

Frequency of seizure was another factor associated with quality of life. Those who had seizure frequency greater than or equal to one seizure/month were twice more likely to have poor quality of life as compared to patients with no seizure in one year period ( $\mathrm{AOR}=2.25,95 \% \mathrm{CI}$ : 1.19, 4.26).

Similarly patients who were taking two or more than two types of antiepileptic drugs were twice more likely to have poor quality of life as compared to patients who were taking one type of antiepileptic drug $(\mathrm{AOR}=1.81,95 \% \mathrm{CI}$ : 1.02,3.22).

It is indicated that patients who had co-morbid anxiety were about 4.4 times more likely to have poor quality of life as compared to patients who had no anxiety $(\mathrm{AOR}=4.49,95 \% \mathrm{CI}: 2.39,8.44)$ as well as patients who had co-morbid depression were 9.6 times more likely to have poor quality of life as compared to patients who had no depression $(\mathrm{AOR}=9.62,95 \% \mathrm{CI}: 4.86,19.05)$.

Moreover, patients who perceived stigma were twice more likely to have poor quality of life as compared to patients who didn't perceived stigma $(\mathrm{AOR}=2.14,95 \% \mathrm{CI}$ : $1.24,3.67)$. On the other hand, age of respondents, occupation, monthly income, side effects of AEDs, age at onset of illness and duration of AEDs had no statistically significant association with quality of life on multivariate logistic regression

Table 4. Bivariate and Multivariate analysis of variables associated with quality of life among epileptic patients at AMSH, Addis Ababa Ethiopia, 2013 $(n=415)$

\begin{tabular}{|c|c|c|c|c|c|}
\hline \multirow{2}{*}{ Variable } & & \multicolumn{4}{|c|}{ Quality of life } \\
\hline & & Poor & Good & $\operatorname{COR}(95 \% \mathrm{CI})$ & AOR (95\%CI) \\
\hline \multirow{4}{*}{ Age } & $18-24$ & 48 & 82 & 1 & 1 \\
\hline & $25-34$ & 82 & 95 & $1.47(0.92,2.34)$ & $1.06(0.55,2.05)$ \\
\hline & $35-44$ & 42 & 26 & $2.76(1.50,5.05)$ & $2.20(0.92,5.27)$ \\
\hline & $45+$ & 18 & 22 & $1.39(0.68,2.86)$ & $1.61(0.57,4.54)$ \\
\hline \multirow{4}{*}{ Education } & Unable to read \&write & 26 & 9 & $7.15(2.87,17.80)$ & $4.69(1.38,15.87)^{*}$ \\
\hline & primary school & 81 & 70 & $2.86(1.57,5.21)$ & $3.51(1.57,7.82)^{*}$ \\
\hline & Secondary school & 62 & 94 & $1.63(0.89,2.97)$ & $1.24(0.55,2.79)$ \\
\hline & Diploma \&above & 21 & 52 & 1 & 1 \\
\hline \multirow{2}{*}{ Occupation } & With Job & 139 & 185 & 1 & 1 \\
\hline & Without Job & 51 & 40 & $1.69(1.06,2.71)$ & $0.62(0.30,1.27)$ \\
\hline \multirow{4}{*}{ Monthly Income } & $<200$ & 68 & 49 & $5.16(2.73,9.76)$ & $2.21(0.81,6.02)$ \\
\hline & $200-500$ & 63 & 47 & $4.98(2.62,9.49)$ & $2.29(0.93,5.62)$ \\
\hline & $501-1000$ & 41 & 62 & $2.46(1.28,4.72)$ & $1.78(0.75,4.21)$ \\
\hline & $>1000$ & 18 & 67 & 1 & 1 \\
\hline \multirow{3}{*}{ Frequency of attack } & $\geq 1 /$ month & 138 & 90 & $5.06(3.11,8.23)$ & $2.25(1.19,4.26)^{*}$ \\
\hline & 1-3/year & 22 & 36 & $2.02(1.03,3.93)$ & $1.06(0.44,2.53)$ \\
\hline & Seizure free/year & 30 & 99 & 1 & 1 \\
\hline \multirow{2}{*}{ Type of drugs } & One & 90 & 167 & 1 & 1 \\
\hline & $\geq$ two & 100 & 58 & $3.2(2.12,4.83)$ & $1.81(1.02,3.22)^{*}$ \\
\hline \multirow{2}{*}{ Side effects of AED } & Yes & 119 & 78 & $3.15(2.11,4.72)$ & $1.12(0.63,2.01)$ \\
\hline & No & 71 & 147 & 1 & 1 \\
\hline \multirow{3}{*}{ Medication duration } & $\leq 5$ years & 94 & 138 & 1 & 1 \\
\hline & $5-10$ years & 42 & 37 & $1.66(0.99,2.78)$ & $1.97(0.98,3.97)$ \\
\hline & $\geq 11$ years & 54 & 50 & $1.58(0.99,2.52)$ & $1.80(0.92,3.50)$ \\
\hline \multirow{2}{*}{ Anxiety } & Yes & 111 & 28 & $9.88(6.05,16.13)$ & $4.49(2.39,8.44)^{*}$ \\
\hline & No & 79 & 197 & 1 & 1 \\
\hline \multirow{2}{*}{ Depression } & Yes & 120 & 16 & $22.39(12.44,40.30)$ & $9.62(4.86,19.05)^{*}$ \\
\hline & No & 70 & 209 & 1 & 1 \\
\hline \multirow{2}{*}{ Perceived stigma } & Yes & 106 & 63 & $3.24(2.15,4.88)$ & $2.14(1.24,3.67)^{*}$ \\
\hline & No & 84 & 162 & 1 & 1 \\
\hline
\end{tabular}

Note: ${ }^{*}$ represents variables having statistically significant association. Reference groups.1

\section{Discussion}

In the current study, the result showed that the mean quality of life was 56.36 which ranges from 52.1-61.8 across four domains and this study was consistent with the study conducted in Sudan with the same instrument score for all domains were (50.6-60.8) [13].

However, in the present study the mean quality of life was higher than the study done in Kenya as mean QOL among people living with epilepsy was 49.90 [14]. The possible reason for the difference might be the Kenya study inclusion criteria were patients who had taken Anti 
Epileptic Drugs (AEDs) for at least two years as this revealed in various literatures longer duration of illness was associated with poor quality of life[15-17]. The second reason might be the use of poly AEDs therapy large (54\%) in Kenya as compared from current study (38.1\%). Different literatures [17-20] suggested that polytherapy receiving patients had lower mean QOL score as compared to their counterpart.

The finding of this study is lower than the result reported from Tunisia, china and Indonesia which showed mean overall score of $64.4,64.3$ and 67.6 respectively[21$23]$.The possible reasons for the differences might be in Indonesia, the inclusion criteria were with minimum education level of junior high school. This could be because more educated patients are more aware of taking medication on time and are better to understand the precipitating and aggravating factors of the disease and also know that regular follow up with treatment can avoid seizures[24, 25]. The second justification might be majority of $(85.5 \%)$ the patients in Indonesia were on single drug treatment in contrast to the present study $(61.9 \%)$ which increases their mean QOL score as compared to patients with multi-drug treatments [20] and prescription of multiple drugs can result in multiple adverse side effects and have a negative effect on QOL[6, 21]. The last possible reason could be this cross-sectional study was conducted using WHOQOL-BREF, but that of China and Indonesia were conducted using Quality of Life Inventory for Epilepsy (QOLIE-31) and using SF-36 in Tunisia.

In this study, patients educated from below than secondary school were found to have poor quality of life compared to diploma and above which is consistent with the study done in Iraq [6].

Regarding clinical factors, types of AEDs and frequency of seizure were associated with quality of life in this study. When QOL was assessed in relation to types of drugs, it was found that patients taking two or more than two AEDs had poor QOL score as compared to patients on single drug. This finding was consistent with many previous studies $[6$, 19, 22, 23].

Moreover, in this study, most of the respondents (54.9\%) who had frequent seizures reported poor QOL. This result was similar with many previous studies [14, 17, 19, 21, 22].

Co-morbidity of depression and anxiety were found to be strongly associated with QOL in this study supported with large number of previous studies [19, 23, 26, 27].

The results of the present study also revealed that the QOL is significantly influenced by felt stigmatization about their epilepsy; which is in line with study done in Mangalore city of south India[24].

\section{Conclusion}

Poor quality of life was found to be high on epilepsy patients in this study. Low level of education, frequent attacks of seizure, treatment with two or more drugs, comorbid anxiety and depression, and also those with perceived stigma were significantly associated with poor quality of life. Clinicians should manage patients with epilepsy to become seizure free period and early recognition of co morbid psychiatric illness like depression and anxiety in people with epilepsy should be of great concern for health care providers.

\section{Acknowledgments}

We would like to acknowledge University of Gondar and Amanuel Mental Specialized Hospital for financial support. Our deepest gratitude also goes to those who participated in this study.

\section{References}

[1] WHO: Atlas: Epilepsy care in the world. Geneva, Switzerland: World Health Organization Press. 2005.

[2] InternationalLeagueAgainstEpilepsy.: Quality of Life: General Considerations. Epilepsia 2003, 44(6):57-58.

[3] Baskind R, Birbeck GL: Epilepsy-associated stigma in subSaharan Africa:The social landscape of a disease. Epilepsy \& Behavior 2005, 7:68-73.

[4] Sibat H: Novel aspect of epilepsy: In tech 2011.

[5] WHO: Division Of Mental Health And Prevention Of Substance Abuse: WHOQOL User Manual.Geneva, Switzerland. 1998.

[6] Rajabi F, Dabiran S, Hatmi ZN, Zamani G: Quality of Life of Epileptic Patients Compared to General Population in Tehran. Acta Medica Iranica 2009, 47(1):75-78.

[7] Chin JH: Epilepsy treatment in sub-Saharan Africa: closing the gap. African Health Sciences 2012, 12(2):186 - 192.

[8] Skevington SM, Lotfy M, O'Connell KA: The World Health Organization's WHOQOL-BREF quality of life assessment: Psychometric properties and results of the international field trial A Report from the WHOQOL Group. Quality of Life Research 2004, 13:299-310.

[9] Billington DR, Landon J, Krägeloh CU, Shepherd D: The New Zealand World Health Organization Quality of Life (WHOQOL) Group. The New Zealand Medical Journal 2010, 123(1315).

[10] Higginson IJ, Carr AJ: Measuring quality of life: using quality of life measures in the clinical setting. BMJ 2001, 322: $1297-1300$.

[11] Deribew A, Tesfaye M, Hailmichael Y, Negussu N, Daba S, Wogi A, Belachew T, Apers L, Colebunders R: Tuberculosis and HIV co-infection: its impact on quality of life. Health and Quality of Life Outcomes 2009, 7:105.

[12] Reda AA: Reliability and Validity of the Ethiopian Version of the Hospital Anxiety and Depression Scale (HADS) in HIV Infected Patients. PLOS ONE 2011, 6(1):e16049.

[13] Ohaeri JU, AwadallaAW, Farah AA: Quality of life in people with epilepsy and their family caregivers: An Arab experience using the short version of WHO Quality of Life Instrument. Saudi Med J 2009, 30(10):1328-1335. 
[14] Kinyanjui DW, Kathuku DM, Mburu JM: Quality of life among patients living with epilepsy attending the neurology clinic at kenyatta national hospital, Nairobi, Kenya: a comparative study. Health and Quality of Life Outcomes 2013, 11:98.

[15] Djibuti M, Shakarishvili R: Influence of clinical, demographic, and socioeconomic variables on quality of life in patients with epilepsy: findings from Georgian study. $J$ Neurol Neurosurg Psychiatry 2003, 74:570-573.

[16] Senol V, Soyuer F, Arman F, O"ztu“"rk A: Influence of fatigue, depression, and demographic, socioeconomic, and clinical variables on quality of life of patients with epilepsy. Epilepsy \& Behavior 2007, 10:96-104.

[17] Sinha A, Sanyal D, Mallik S, Sengupta P, Dasgupta S: Factors associated with quality of life of patients with epilepsy attending a tertiary care hospital in Kolkata,India. Neurology Asia 2011, 16(1):33-37.

[18] Baker GA, Jacoby A, Gorry J, Doughty J, Ellina V: Quality of Life of People with Epilepsy in Iran, the Gulf,and Near East. Epilepsia 2005, 46(1):130-140.

[19] Mosaku KS, Fatoye FO, Komolafe M, Lawal M, Ola BA: Quality of life and associated factors among adults with epilepsy in Nigeria. Int J Psychiatry Med 2006, 36(4):469481.

[20] Wang T, Wang H, Cheng J: Eleven influential factors for quality of life in adults with epilepsy. Neural Regen Res 2008, 3(4):422-426.
[21] Mrabet H, Mrabet A, Zouari B, Ghachem R: Health-related Quality of Life of People with Epilepsy Compared with a General Reference Population: A Tunisian Study. Epilepsia 2004, 45(7):834-843.

[22] Hawari I, Syeban Z, Lumempouw SF: Low education, more frequent of seizure, more types of therapy, and generalized seizure type decreased quality of life among epileptic patients Med J Indones 2007 16(2):101-103

[23] Kwan P, Yu E, Leung H, Leon T, Mychaskiw MA: Association of subjective anxiety, depression, and sleep disturbance with quality-of-life ratings in adults with epilepsy. Epilepsia 2009, 50(5):1059-1066.

[24] Joseph N, Ray A, Reshma BK, Bhat S, Herady M, Kumar A, Kiran K S: Assessment of quality of life, stigma associated and self-management practices among patients suffering from epileptic seizures: A cross sectional study. Journal of Neuroscience and Behavioural Health 2011, 3(7):91-98.

[25] Shakir M, Al-Asadi J: Quality of Life and its Determinants in People with Epilepsy in Basrah, Iraq. Sultan Qaboos University Med J 2012, 12(4):449-457.

[26] Salgado PCB, Cendes F: The effects of epileptic seizures upon Quality of Life. J Epilepsy Clin Neurophysiol 2009, 15(3):110-113.

[27] Phabphal K, Geater A, Limapichart K, Satirapunya P, Setthawatcharawanich S: Quality of Life in Epileptic Patients in Southern Thailand. J Med Assoc Thai 2009, 92(6): 762-769. 